\title{
A Rosid Is a Rosid Is a Rosid . . . or Not
}

\author{
Rebecca Green \\ Assistant Editor, Dewey Decimal Classification, \\ OCLC Online Library Computer Center, Inc. \\ Dewey Editorial Office, LM-548, Library of \\ Congress, 101 Independence Ave., S.E., \\ Washington, DC, 20540-4330 USA \\ $+1-202-707-6983$ \\ greenre@oclc.org
}

\author{
Giles Martin \\ Consulting Assistant Editor, \\ Dewey Decimal Classification \\ 1 Corona Street, \\ Hamilton East NSW 2303, Australia \\ $+61-2-4961-1972$ \\ ozin0h@yahoo.com
}

\begin{abstract}
The current structure of 583 Magnoliopsida (Dicotyledons) and 584 Liliopsida (Monocotyledons) in the Dewey Decimal Classification (DDC) system reflects changes made when the life sciences were thoroughly revised in 1996. Since that time, considerable progress has been made in the phylogenetic classification of angiosperms (flowering plants). In particular, APG III, the 2009 version of the classification developed by the Angiosperm Phylogeny Group, is finding use as a tool to organize both botanical information and botanical collections. The Dewey Editorial Office has received a request to revise 583-584 in light of this taxonomy "as appropriate"; relevant revisions would be likely to include both structural and terminological changes. In deciding how to provide accommodation for APG III, the Dewey editorial team must address many issues: Is APG III now stable enough and accepted broadly enough to be adopted as the basis for a major revision of the DDC? Should revisions in 583-584 be coordinated with parallel revisions in other parts of the life sciences? What revision strategies can be considered in revising 583-584 to accommodate APG III? What are their various strengths and weaknesses? How have other major classification schemes (e.g., the UDC) accommodated APG III? Discussion of these issues is guided by the principles ("editorial rules") that govern development of the DDC.
\end{abstract}

\section{Keywords}

Dewey Decimal Classification, DDC, classification revision, botanical taxonomy, APG III, angiosperms.

\section{INTRODUCTION}

Advances in knowledge are problematic for the ongoing development of bibliographic classification schemes. But

This is the space reserved for copyright notices.

Advances in Classification Research, 2012, October 26, 2012, Baltimore, MD, USA.

Copyright notice continues right here. when advances focus on the classification of the field of study, the problems are particularly thorny, as is the case in the classification of angiosperms (flowering plants). The work of Swedish botanist Linnaeus, from which stems all modern biological classification, relied on morphological similarities between organisms to establish groupings among them. During the 20th century (especially its latter decades), biological classification in general and botanical classification in particular has shifted away from a reliance on morphological similarities toward an emphasis on shared derived characteristics, that is, on features inherited from a common ancestor, an approach referred to as phylogenetic classification. Molecular phylogeneticists process DNA sequence data to determine evolutionary relationships (Nickrent, 2011).

The current structure of 583 Magnoliopsida (Dicotyledons) and 584 Liliopsida (Monocotyledons) in the Dewey Decimal Classification (DDC) system reflects changes made when the life sciences were thoroughly revised in 1996 (see New, 1996). This structure is based on the arrangement found in the article "Angiosperms" in The New Encyclopedia Britannica (NEB) (1989), except that the basic outline from early editions was retained for 584 . The NEB arrangement is based in turn on the plant classification of Armen Takhtajan, first published in Russian in 1967 and translated into English under the title Flowering plants: origin and dispersal in 1969.

On the one hand, the DDC's division of angiosperms into monocotyledons and dicotyledons is based on a morphological similarity approach, taking into account the following characteristics: number of embryonic "seed leaves" (cotyledons); pollen structure; number of flower parts; arrangement of leaf veins; stem vascular arrangement; root development; and secondary growth (UCMP, n.d.). On the other hand, Peter H. Raven (2009), director of the Missouri Botanical Garden, writes that "Takhtajan's most important achievement has been the development of his phylogenetic system of the flowering plants, a system that has greatly influenced all other recent systems of classification." In other words, the taxonomic structure underlying 583 and 584 at present reflects morphological similarities and evolutionary relationships. 
Green, R., \& Martin, G. (2013). A Rosid Is a Rosid Is a Rosid . . or Not. Advances In Classification Research Online, 23(1), pp. 9-16. doi:10.7152/acro.v23i1.14228

In recent years, angiosperm classification has been a very active area of research. Indeed, the number of flowering plant classifications has blossomed: an article entitled "Summary of recent systems of angiosperm classification" (Reveal, 2011) refers to seven systems established between 2007 and 2010 and then presents yet another (an eighth) system. This proliferation of activity notwithstanding, the current version of the classification produced by the Angiosperm Phylogeny Group (2009), commonly referred to as APG III, is distinguished among these classifications as the product of an international group of botanists, a classification expressly developed to reflect the consensus of the botanical community. Hence, the Dewey editorial team is investigating whether and how to revise 583-584 in DDC 23 (the current edition) in light of the APG III taxonomy.

In considering what accommodation of APG III to provide, the Dewey editorial team must consider the stability of APG III, as well as its breadth of acceptance. Whether revisions in 583-584 should await similar revisions in other parts of the life sciences should also be considered. The strengths and weaknesses of possible revision strategies need to be investigated, an endeavor that can be informed by revisions recently made in the UDC botany schedules. The entire process will be undertaken in the light of the principles ("editorial rules") governing DDC development..

\section{BACKGROUND}

\section{Taxonomic levels}

Traditional ("rank-based") biological taxonomies are organized hierarchically, with the rank (e.g., kingdom, phylum, class, order, family, genus, species) of a taxonomic unit / taxon indicating its relative position in the taxonomy. Angiosperms are a major grouping within the plant kingdom, roughly at the phylum level. Within the DDC, angiosperms are developed to the level of orders and families; the APG III classification likewise focuses on orders and families. In neither case is rank of absolute import.

\section{Monophyly}

Phylogenetic taxonomy distinguishes among monophyletic, paraphyletic, and polyphyletic taxa. A monophyletic group (or 'clade') consists of all the descendants of a closest common ancestor; the APG recognizes only monophyletic groups. A paraphyletic group is almost monophyletic, but fails the definitional test through exclusion of one or more descendants. Dicotyledons are paraphyletic via their exclusion of monocotyledons and consequently are not recognized in modern phylogenetic taxonomies. (To be complete: A polyphyletic group is a taxon that is neither monophyletic nor paraphyletic.) Within angiosperms, APG III recognizes three major (eudicots ['true dicots'], monocots, and magnoliids) and five minor monophyletic groups; the smallest comprises a single species only, while the largest comprises ca. 175,000 species.

\section{Nomenclature}

In rank-based, binomial, nomenclature, the formal name of a taxon includes (1) a type (the types of families are genera; the types of genera are species, etc.) and (2) a rank (Lee \& Skinner, 2007); rank-based names thus reflect taxonomic structure. Phylogenetic nomenclature is tied to the circumscription of specific clades and is not expressive of rank. Fortunately, in cases where the membership of a rank-based taxon and a phylogenetic taxon are similar, their names are likely to reflect the close correspondence. If the DDC adopts phylogenetic taxa, names/captions will change, but in many cases only minimally.

\section{STABILITY OF APG III}

APG III is not the last word on angiosperm classification. For example, some families are still unplaced as to order in APG III. But the paper accompanying the presentation of APG III forecasts stability in the classification: "We do not see the APG classification as continuing to mutate for the indefinite future. . . . We hope the classification below will be found to be reasonable and, hence, will not need much further change" (p. 106).

As new studies resolve problems in angiosperm classification (e.g., unplaced taxa), results are incorporated into, for example, Rydeheard (2011) and the Angiosperm Phylogeny Website (APWeb). Peter Stevens (2012), APG member and maintainer of APWeb, writes there:

All clades are hypotheses of relationships, and as hypotheses they may be overturned. . . . Changes in our ideas of relationships, and hence in the clades we talk about, are particularly likely in parts of Caryophyllales and Malpighiales. Taxa whose relationships are still largely unknown or only partly known - apparently not many, although we must expect to find a few more seriously misplaced genera-should also not be forgotten. Thus some changes are to be expected ...

The likely changes in Caryophyllales referred to here could affect the placement of families in that order, but the relationship changes in Malpighiales are internal to the order and unlikely to affect family placement in the order (Peter Stevens, personal communication).

Additionally, several of the principles guiding the development of APG III-formal recognition only of easily recognizable taxa, preservation of groups that are well established in the literature, and minimization of nomenclature changes-rein in the degree of change potentially associated with such a revision.

\section{ACCEPTANCE OF THE APG}

A 2009 Royal Botanic Gardens, Kew press release (Friedlander et al., 2009) introduced the current version of the APG:

Scientists from the Royal Botanic Gardens, Kew (RBG Kew) have led a significant global revision of the system which botanists use to classify flowering plants. This 
Green, R., \& Martin, G. (2013). A Rosid Is a Rosid Is a Rosid . . or Not. Advances In Classification Research Online, 23(1), pp. 9-16. doi:10.7152/acro.v23i1.14228

work ... will have a fundamental impact, not only on scientists, but on the way that botanic gardens organise their collections and future use of plant information to improve human quality of life.

Consistent with this prediction, the APG III classification has been adopted as a reference tool for organizing botanical information. For example:

- The Plant List (2010) is intended to be a working list of all known plant species. "Collaboration between the Royal Botanic Gardens, Kew and Missouri Botanical Garden enabled the creation of The Plant List by combining multiple checklist datasets held by these institutions and other collaborators. . . Genera and species are presented in families which follow the source database(s) except in the case of Angiosperms where we have, wherever possible allocated accepted genera to the families recognised by the Angiosperm Phylogeny Group."

- The family circumscriptions in the World Checklist of Selected Plant Families (WCSP 2012; also from Royal Botanic Gardens, Kew) follow APG III.

- The third edition of Stace's (2010) New Flora of the British Isles has adopted the APG III system as its basis for angiosperms.

- A photographic survey of angiosperms in the US and Canada (Spears, 2006) is organized using APG II (the latest version available at the time of publication).

The APG III classification has also been used to (re-) organize botanical collections, based on Haston et al.'s (2009) transformation of the tree-like APG II classification into a linear arrangement. According to the RBG Kew press release, herbarium collections adopting it include RBG Kew, RBG Edinburgh, the Natural History Museum (London), the Musée National d'Histoire naturelle (Paris), Conservatoire et Jardin Botaniques (Geneva), the Nationaal Herbarium Nederland (Leiden, Utrecht and Wageningen), and the Natural History Museum in London. The press release goes on to argue for more widespread use:

Such convergence on a single system of ordering collections with agreed circumscriptions of the families within it has never occurred previously, and this should provide the impetus for other herbaria also to accept this method of organising their collections.

Several of the APG classification uses noted here are connected with institutions at which APG authors and contributors are resident. On the one hand, determining the breadth of acceptance of APG III beyond those institutions is difficult. On the other hand, the phylogenetic approach of APG III is clearly consistent with modern principles of classification; moreover, significant advancements in the classification of angiosperms have taken place since the major revision of the life sciences included in DDC 21.
Although we cannot judge the degree of acceptance of APG III in the botanical community directly, we can gather relevant bibliographic data. Table 1 displays the results of searching WorldCat for rank-based-specific terminology and the corresponding phylogenetic-specific terminology over three recent time periods. (The counts for rank-based terminology for 2010-2012 omit a large set of archival material from the 1960s.) Modification of 583-584 to accommodate APG III is supported by the general trend of decreasing use of rank-based terminology and increasing use of phylogenetic terminology over these time periods.

\begin{tabular}{|l|c|c|c|}
\hline & $\begin{array}{c}\mathbf{2 0 0 0 -} \\
\mathbf{2 0 0 4}\end{array}$ & $\begin{array}{c}\mathbf{2 0 0 5 -} \\
\mathbf{2 0 0 9}\end{array}$ & $\begin{array}{c}\mathbf{2 0 1 0} \\
\mathbf{2 0 1 2}\end{array}$ \\
\hline Rank-based terminology & & & \\
\hline Asteridae & 15 & 37 & 6 \\
\hline Commelinidae & 49 & 16 & 2 \\
\hline Dicotyledon(s) & 908 & 850 & 103 \\
\hline Magnoliidae & 15 & 6 & 3 \\
\hline Rosidae & 12 & 5 & 3 \\
\hline Phylogenetic terminology & & & \\
\hline Asterid(s) & 6 & 17 & 16 \\
\hline Commelinid(s) & 1 & 6 & 9 \\
\hline Eudicot(s) & 8 & 115 & 76 \\
\hline Magnoliid(s) & 0 & 16 & 14 \\
\hline Rosid(s) & 7 & 45 & 26 \\
\hline
\end{tabular}

Table 1. Comparative terminology trends in WorldCat.

Table 2 displays counts for angiosperm orders newly recognized in the APG system (i.e., in APG I, APG II, or APG III). Sixty percent of these orders now appear in bibliographic records; of these, several have achieved semirobust literary warrant levels.

\begin{tabular}{|l|c|c|c|}
\hline $\begin{array}{l}\text { Newly recognized } \\
\text { APG orders }\end{array}$ & $\begin{array}{c}\mathbf{2 0 0 0 -} \\
\mathbf{2 0 0 4}\end{array}$ & $\begin{array}{c}\mathbf{2 0 0 5}- \\
\mathbf{2 0 0 9}\end{array}$ & $\begin{array}{c}\mathbf{2 0 1 0} \\
\mathbf{2 0 1 2}\end{array}$ \\
\hline Amborellales & 0 & 4 & 3 \\
\hline Berberidopsidales & 0 & 22 & 3 \\
\hline Bruniales & 0 & 0 & 0 \\
\hline Buxales & 0 & 17 & 3 \\
\hline Chloranthales & 0 & 0 & 0 \\
\hline Ceratophyllales & 0 & 5 & 4 \\
\hline Escalloniales & 0 & 0 & 0 \\
\hline Huerteales & 0 & 0 & 0 \\
\hline Nymphaeales & 3 & 15 & 8 \\
\hline Paracryphiales & 0 & 0 & 0 \\
\hline Petrosaviales & 0 & 0 & 2 \\
\hline Picramniales & 0 & 0 & 0 \\
\hline Trochodendrales & 0 & 1 & 2 \\
\hline Vitales & 0 & 7 & 1 \\
\hline Zygophyllales & 0 & 13 & 4 \\
\hline
\end{tabular}

Table 2. Literary warrant counts in WorldCat for newly recognized APG orders.

\footnotetext{
${ }^{1}$ Search limited to works classed in the 580s, to avoid titles
} like España: los años vitales and Dick Vitale's basketball. 
Green, R., \& Martin, G. (2013). A Rosid Is a Rosid Is a Rosid . . or Not. Advances In Classification Research Online, 23(1), pp. 9-16. doi:10.7152/acro.v23i1.14228

\section{COORDINATION OF REVISION}

While analysis of DNA sequence data has also been undertaken in areas outside angiosperms, we are unaware of other areas in which classifications have been developed with the aim of reflecting the consensus of the relevant subcommunity. We hope such classifications will emerge over time, but cannot predict when they will be developed and for which groups of organisms. Optimally, a consensus classification will eventually emerge for all groups of organisms. Blaxter (2004) suggests, "Advances in highthroughput sequencing methodologies . . p place the idea of a universal, multi-locus molecular barcoding system in the realm of the possible." We assume, however, that we should not refrain from making interim changes while awaiting such a development; even under optimal conditions, development of such a system and consensual interpretation of its results are likely to be years away.

Does the possibility of a universal phylogenetic classification herald the time when biological classification will be both complete and stable? Unfortunately, this hope is not justified for at least two reasons. First, analysis of DNA sequence data is performed using models of DNA sequence evolution. Multiple models exist now, and new models will almost surely be proposed in the future. But different models lead to different outcomes (just as different weather models lead to different weather predictions). Second, as new species (both living and extinct) are discovered, the data sets being analyzed change. For example, between 2000 and 2011, 17,814 new species were discovered on average each year; approximately half were insects and over one-tenth were plants (including flowering plants) (IISE/ASU, 2008-2012). Biological classification in general and botanical classification in particular are thus unlikely ever to be "done."

These insights lead us to conclude that the accommodation of APG III can be undertaken based on criteria local to 583 and 584, without awaiting parallel progress in the classification of other plants/organisms. On the one hand, current needs warrant undertaking at least some revision sooner than later; on the other hand, further need for revision will continue to arise, perhaps indefinitely.

\section{ACCOMMODATION STRATEGIES}

The editorial rules that guide development of the DDC recognize several levels of revision:

- Complete revision: Base number remains unchanged, but most subdivisions are changed.

- Extensive revision: Base number and overall outline retained, but many subdivisions change.

- Moderate revision: Regularization of structure, expansions, and reductions undertaken as needed.

Logically speaking, our possible courses of action in accommodating APG III range along a continuum. For purposes of discussion, we would like to identify four general positions on that continuum (in the discussion below, the current system is referred to as the "NEB system" since that is what is treated as authoritative in Dewey):

1. Retain the NEB system as the basis for 583-584, adding APG III terminology where the two systems share sufficiently similar taxa and relationships among the taxa.

2. Retain the NEB system as the basis for 583-584, mentioning all taxa at the ranks of order or family that are in APG III, but not NEB, in notes. Given some degree of incongruence between NEB and APG III, these notes will sometimes appear in conjunction with classes that are merely the least bad choice.

3. Revise 583-584 on the basis of APG III, but minimize relocations. Use see references to establish the APG III logical hierarchy, as needed.

4. Establish the APG III taxonomy as the basis for 583-584, adding/retaining NEB terminology where the two systems share sufficiently similar taxa and relationships among the taxa.

Both options 1 and 2 could probably be undertaken as moderate revisions, while option 3 would call for extensive revision, and option 4 would translate into a complete revision.

The strengths and weaknesses of the four options enumerated above are affected by the following:

1. The approach taken to plant taxonomy with APG III is consistent with the principles of modern systematic biology. This argues against options 1 and 2, and for options 3 or 4 .

2. APG III is still a young taxonomy. We can expect to see further revisions-perhaps within the near-term future. This argues for options 1 and 2, and against options 3 and 4

3. All other things being equal, we would prefer not to relocate topics, (a) as a general principle, (b) because of the revision undertaken as part of the DDC 21, and (c) because the monographic literature in this area tends to be retained by research libraries. This argues against options 3 and especially 4.

4. APG III includes a significant number of orders and families not in the current 583-584 arrangement; at the same time, when orders and families of the same name exist in the two systems, the relationships that exist in the current arrangement often differ from those in APG III. That is, APG III may use the same terminology to denote larger or smaller groupings. For example, in APG III the order Poales includes what NEB places in other orders, including Commelinales. To be precise about this, we would need to distinguish "Poales (in the rank-based sense)" from "Poales (in the phylogenetic sense)." This argues against option 2 . 
Green, R., \& Martin, G. (2013). A Rosid Is a Rosid Is a Rosid . . or Not. Advances In Classification Research Online, 23(1), pp. 9-16. doi:10.7152/acro.v23i1.14228

Viewed alternatively from the vantage point of the four options:

Option 1. This option would probably serve mainly as a delaying tactic, since among systematists use of systems such as Cronquist and pre-2009 Takhtajan appears to be giving way (at least to a degree) to use of an APG-based taxonomy. This option avoids relocations, but may offer only minimal help in classifying the APG-oriented literature.

Option 2. Given the incongruence between NEB and APG III, the mention of APG taxa in notes will sometimes appear in conjunction with classes that are merely the least bad choice for them. This is either a delaying tactic, like option 1 , or looks to commit the DDC to staying with a rank-based taxonomic structure indefinitely.

Option 3. This option would include some number of relocations, but not so many as in option 4 . On the one hand, it would provide adequate coverage of APG taxa; on the other hand, it would to some degree retain NEB as the basis for the structure of 583-584.

Option 4. This option would require significant relocation and/or immediate reuse. While adopting a modern basis for the development in 583-584, it would still be subject to future revisions.

Our sense is that, while none of the options is perfect, option 3 probably represents the best compromise. In this context, wisdom dictates (1) avoiding relocations in areas where subsequent relocations would be likely and (2) omitting mention of newly recognized families without literary warrant.

\section{EXAMPLE REVISIONS}

Practically speaking, what would be involved in a revision of 583-584 based on option 3? In order to demonstrate this more clearly, we limit our discussion to the supraordinal rosid clade, roughly equivalent to the current 583.7 Rosidae and 583.8 Other orders of Rosidae. If possible, we should keep rosids within this same notational range. This desideratum presents some challenge: rosids comprise over one-quarter of all angiosperm species, but only one-tenth of the angiosperm notational space.

\section{Terminology}

Our first accommodation would be to change the caption at 583.7 to "Rosids" (but see further under Circumscription) and the caption at 583.8 to "Other orders of Rosids."

\section{Circumscription}

Close at hand is the need to circumscribe "rosids." At least three definitions are in current use: one excludes Saxifragales and Vitales (Stevens, 2012); one includes Saxifragales, but excludes Vitales (Burleigh et al., 2009); one includes Vitales, but excludes Saxifragales (APG III). (Hence, a rosid is a rosid is a rosid . . . or not.) Vitales is currently in standing room at 583.86 Rhamnales (its single family, Vitaceae, is mentioned in the including note there). The current notational hierarchy also makes 583.72 Saxifragales part of Rosidae. Adopting an APG III basis would call for relocating Saxifragales outside of 583.7 and 583.8. An alternative treatment is to expand the scope of 583.7 to Rosids and Saxifragales.

\section{Accommodation of newly recognized orders}

Of the fourteen orders newly recognized among angiosperms, three are rosids: Huerteales, Picramniales, and Zygophyllales. (Technically, Vitales is also newly recognized, but as just noted, where it belongs in the current DDC development is clear and without controversy.) The recognition of two other rosid orders, Oxalidales and Crossosomatales, predates APG, but they are not currently mentioned in the DDC. The real estate in 583.7-583.8 is already densely occupied: orders are associated with the notation one level below 583.7 and 583.8 , with the only notation currently open there at 583.81 and 583.83. How then can we accommodate these additional orders?

The most sensible tactic is to gather several orders into a class number at the relevant notational level, with the specific orders one level further down. For example, currently we have the following class:

\subsection{Sapindales}

We can accommodate several of the new-to-the-DDC orders in this manner:

\subsection{Crossosomatales, Huertales, Picramniales, Sapindales}

583.782 Crossosomatales

583.784 Picramniales

583.786 Sapindales

583.788 Huertales

In a similar fashion, the current class at:

583.82 Minor orders of Rosidae

could be redefined and restructured as:

583.82 Oxalidales and Zygophyllales

583.822 Zygophyllales

583.825 Oxalidales

\section{Relocations}

Although APG III does not identify Malpighiales as a newly recognized order (the name had been used-with a different circumscription - in the mid-1900s), its emergence as a rosid order is not reflected in the current DDC angiosperm development. However, many of the ca. 35 families placed in Malpighiales by APG III are currently recognized in the DDC. Here are the classes in which those families are currently located: 
Green, R., \& Martin, G. (2013). A Rosid Is a Rosid Is a Rosid . . or Not. Advances In Classification Research Online, 23(1), pp. 9-16. doi:10.7152/acro.v23i1.14228

\subsection{Rafflesiaceae \\ 583.624 Bonnetiaceae, Caryocaraceae, Clusiaceae, Elatinaceae, Hypericaceae, Medusagynaceae, Ochnaceae \\ 583.625 Lacistemataceae, Violaceae \\ 583.626 Achariaceae, Malesherbiaceae, Passifloraceae, Turneraceae \\ 583.65 Salicaceae}

583.69 Dichapetalaceae, Euphorbiaceae, Pandaceae, Picrodendraceae

583.73 Chrysobalanaceae

583.763 Rhizophoraceae

583.79 Erythroxylaceae, Humiriaceae, Ixonanthaceae, Linaceae, Malpighiaceae

583.82 Podostemales, Trigoniaceae

Since Malpighiales is a large order, it is a viable candidate for 583.83, the highest notation open in 583.7 and 583.8. As the anticipated changes in Malpighiales referred to by Stevens (2012) involve only relationships internal to the order, we can safely relocate these families to 583.83 Malpighiales. Indeed, as only one-third of the families are currently in classes under 583.7 or 583.8 , if we were not to relocate them, the families of Malpighiales would be widely scattered, a state resonating more with option 2 than with option 3.

\section{Accommodation of supraordinal taxa}

Within the rosids, APG III recognizes two groups of orders, the fabids (a.k.a. eurosids I), and the malvids (a.k.a. eurosids II), each of which includes eight orders; neither is currently recognized within the DDC. Given that rosid orders use notation one level below 583.7 and 583.8, it is not possible to accommodate fabids and malvids in the notational hierarchy. A possible solution is to adopt a centered entry for each of the groups of orders, but this works only if three or more of the eight orders appear sequentially. This can readily be made to be the case for malvids, which might be treated in this fashion:

583.64 Brassicales (synonym for current caption)

583.68 Malvales (current)

> 583.76-583.79 Malvids

583.76 Myrtales (current)

583.782 Crossosomatales (newly recognized)

583.784 Picramniales (newly recognized)

583.786 Sapindales (expanded from 583.78)

583.788 Huerteales (newly recognized)

583.79 Geraniales (current)
We are left several straightforward questions:

- Where should comprehensive works on malvids be classed? No place other than 583.7 recommends itself.

- Should Brassicales and Malvales be relocated within the scope of the centered entry? If not, see references should be added from the centered entry to 583.64 and 583.68.

How to handle fabids is less clear. The orders comprising the fabids are currently at or proposed to be at the following numbers:

$\begin{array}{ll}583.46 & \text { Fagales } \\ 583.63 & \text { Cucurbitales } \\ 583.73 & \text { Rosales } \\ 583.74 & \text { Fabales } \\ 583.82 & \text { Oxalidales and Zygophyllales } \\ 583.822 & \text { Zygophyllales } \\ 583.825 & \text { Oxalidales } \\ 583.83 & \text { Malpighiales } \\ 583.85 & \text { Celastrales }\end{array}$

The current entry at 583.84 is not considered a rosid. If the topics there were relocated outside 573.8, we could create a centered entry for fabids at 583.82-583.85, with comprehensive works at 583.8. But this is not a satisfying solution: only half of the relevant orders fall within the centered entry span. Moreover, the orders within the span are new and/or minor. One might choose to relocate 583.46 Fagales and 583.63 Cucurbitales in any case, since their numbers lie outside the notational range for rosids. But we would also like to keep Fagales, Cucurbitales, Rosales, and Fabales close to one another, because of their evolutionary relationships (and also Celastrales, Oxalidales, and Malpighiales close to one another, for the same reason). But would this cause too much relocation?

\section{COMPARISON WITH UDC}

The Universal Decimal Classification (UDC) has recently undertaken significant revision in 582.4/.9, which includes angiosperms (Civallero, 2011). Like the changes we are considering, UDC's revision is grounded in APG III. Like the DDC, the UDC editorial team is concerned with minimizing the disturbance caused users by such a revision. Relocations are being undertaken to empty notation; no notation in current use is to be re-used.

The difficulties inherent in the adoption of a new base classification are evident in differences between how the UDC and the DDC are inclined to handle specific issues: 
Green, R., \& Martin, G. (2013). A Rosid Is a Rosid Is a Rosid . . or Not. Advances In Classification Research Online, 23(1), pp. 9-16. doi:10.7152/acro.v23i1.14228

- Terminology: The UDC prefers the use of Latin scientific names for captions. Since some of the taxa/clades with organizational import in APG III are deemed informal, the UDC has retained older, rankbased, terminology in some cases where the DDC is inclined to adopt APG III terminology. For example, the UDC caption at 582.7 becomes Rosidae (rosids).

- Circumscription: In the UDC, 582.70 Saxifragales is treated as part of 582.7 Rosidae, but the notation for 582.82 Vitales lies outside 582.7 Rosidae.

- Accommodation of newly recognized orders: Of the rosid orders newly recognized in APG III, two (Huerteales, Picramniales) are not mentioned in the UDC revision. Those mentioned have been placed at notation under 582.7 Rosidae, except for Vitales.

- Relocations: Of the families gathered together in Malpighiales by APG III, two-thirds are explicitly mentioned in notation under 582.681 Malpighiales in UDC; the remaining one-third are not explicitly mentioned at all. Note, however, that the notation for Malpighiales lies outside 582.7 Rosidae.

- Accommodation of supraordinal taxa: The UDC has not made accommodation for Fabids, Malvids, or Eurosids.

\section{CONCLUSION}

Since the APG III classification is based on phylogenetic studies and since literary warrant for its taxa are increasing, it is both appropriate and important that the DDC make revisions to accommodate APG III. Such revisions are likely to affect terminology and structure.

The most sensible strategy appears to be to adopt the terminology and structure of APG III orders and families (as modified by sources that keep track of updated work), while minimizing relocations and eschewing immediate reuse. That ongoing maintenance will be necessary is a foregone conclusion.

\section{ACKNOWLEDGMENTS}

We acknowledge the generosity of the UDC editorial team in providing us a customized view of the revisions made in the UDC for 582.4/.9 (UDC MRF, 2012).

\section{REFERENCES}

[APG III] Angiosperm Phylogeny Group III. (2009). An update of the Angiosperm Phylogeny Group classification for the orders and families of flowering plants: APG III. Botanical Journal of the Linnean Society 161, 105-21. Retrieved November 26, 2012 from $<$ http://onlinelibrary.wiley.com/doi/10.1111/j.10958339.2009.00996.x/pdf>.

Blaxter, M.L. (2004). The promise of a DNA taxonomy. Philosophical Transactions of the Royal Society London B Biological Sciences, 2004 April 29; 359(1444): 669679.
Burleigh, J.G.; Hilu, K.W.; \& Soltis, D.E. (2009). Inferring phylogenies with incomplete data sets: a 5-gene, 567taxon analysis of angiosperms. BMC Evolutionary Biology 9: 61. Retrieved November 26, 2012 from < http://www.biomedcentral.com/content/pdf/1471-2148-961.pdf $>$.

Civallero, E. (2011). UDC Biology Revision Project: Second Stage: Class 58 Botany. Extensions and Corrections to the UDC 33,37-40. Retrieved November 26, 2012 from <http://arizona.openrepository.com/ arizona/bitstream/10150/236491/1/Civallero_E\%26C33_ 2011.pdf>.

Friedlander, B.; Phillips, B.; \& Barrowman, T. (2009). As easy as APG III - Scientists revise the system of classifying flowering plants. Royal Botanical Gardens, Kew. Press Release. Retrieved November 26, 2012 from <http://www.kew.org/press/APG_3_pr.html>.

Haston, E.; Richardson, J.E.; Stevens, P.F.; Chase, M.W.; \& Harris, D.J. (2009). The Linear Angiosperm Phylogeny Group (LAPG) III: a linear sequence of the families in APG III. Botanical Journal of the Linnean Society 161, 128-131. Retrieved November 26, 2012 from $<$ http://onlinelibrary.wiley.com/doi/10.1111/j.10958339.2009.01000.x/pdf>.

[IISE/ASU] International Institute for Species Exploration at Arizona State University. (2008-2012). State of Observed Species (SOS) annual reports. Retrieved November 26, 2012 from <http://species.asu.edu/SOS〉.

Lee, M.S.Y.\& Skinner, A. (2007). Stability, ranks and the Phylocode. Acta Palaeontologica Polonica 52: 643-650. Retrieved November 26, 2012 from <http://www. academia.edu/988339/Lee_M.S.Y._Skinner_A._2007._St ability_ranks_and_the_Phylocode._Acta_Palaeontologica _Polonica_52_643-650>.

New, G.R. (1996). Revision and stability in DDC 21: The life sciences catch up. In R. Green (Ed.), Knowledge organization and change: Proceedings of the Fourth International ISKO Conference (pp. 386-395). Frankfurt/Main: Indeks Verlag.

Nickrent, D.L. (2011). A Look at the History of Plant Classification. Lectures notes for Elements of Plant Systematics, Plant Biology 304, Spring 2012, Southern Illinois University, Carbondale. Retrieved November 26, 2012 from <http://www.plantbiology.siu.edu/PLB304/ Lecture03HistTax/HistoryTaxon.html>.

Plant List, The. (2010). Version 1. Retrieved November 26, 2012 from <http://www.theplantlist.org/>.

Raven, P.H. (2009). Foreword to Takhtadzhian, A. L. Flowering plants, pp. vii-ix. New York: Springer.

Reveal, J.L. (2011). Summary of recent systems of angiosperm classification. Kew Bulletin 66, 5-48. Retrieved November 26, 2012 from <http://www. 
Green, R., \& Martin, G. (2013). A Rosid Is a Rosid Is a Rosid . . or Not. Advances In Classification Research Online, 23(1), pp. 9-16.

springerlink.com/content/c583511222gx8g24/fulltext.pdf $>$.

Rydeheard, D.E. (2011). ANGIOSPERMS: The flowering plants: A chart of flowering plant families. Retrieved November 26, 2012 from <http://www.cs.man.ac.uk/ $\sim$ david/flora/chart.pdf $>$.

Spears, P. (2006). A Tour of the Flowering Plants: Based on the Classification System of the Angiosperm Phylogeny Group. St. Louis, Missouri: Missouri Botanical Garden Press.

Stace, C. (2010). New Flora of the British Isles (3rd ed.), Cambridge, UK: Cambridge University Press.

Stevens, P.F. (2012). Angiosperm Phylogeny Website. Version 12. Retrieved November 26, 2012 from <http:// www.mobot.org/MOBOT/research/APweb/>.
Takhtadzhian, A.L. (1969, transl. from the Russian by C. Jeffrey). Flowering plants: Origin and dispersal. City of Washington: Smithsonian Institution Press.

[UCMP] University of California Museum of Paleontology. (n.d.). Monocots versus Dicots: The Two Classes of Flowering Plants. Retrieved November 26, 2012 from < http://www.ucmp.berkeley.edu/glossary/gloss8/monocotd icot.html>.

[UDC MRF] Universal Decimal Classification: Master Reference File: 2011. (2012). The Hague: UDC Consortium.

WCSP. (2012). World Checklist of Selected Plant Families. Facilitated by the Royal Botanic Gardens, Kew. Retrieved November 26, 2012 from <http://apps.kew.org/ wcsp/>. 